\title{
A Comparative Study on the Motivation for Self-Determination of Foreign Students Studying at Korean Universities
}

\author{
Sang-soo $\mathrm{Kim}^{1}$ )
}

\begin{abstract}
The purpose of this study is to examine motivation of Korean language learners according to self determination motivation theory. This study investigated the motivation of foreign students from Kuwait, China, and Vietnam and compare the results. The relationship between the nationality of foreign students and their motivation to learn Korean language was examined. For this purpose, 33 students from Kuwait, 77 from China, and 109 international students from Vietnam were selected as sample of study and their motivation of learning was studied according to their nationalities. The results showed that there were differences between Kuwait students and Chinese students; as well as between Kuwait students and Vietnamese students. However, there was no statistically significant difference in learning motivation between Chinese and Vietnamese students. As a sum, there is a difference in learning motivation and purpose among foreign student from various nationalities who are studying together in Korea. Such difference according to their respective nationalities in deed has a great influence on their motivation of studying abroad.
\end{abstract}

Keywords : Korean Language Class, Korean Language Education, Foreign Students, Motivation, SelfDetermination

\section{Introduction}

As the number of Korean learners continues to increase, learner types such as learner's nationality and learning objectives are also diversifying. In this situation, it is necessary to study the factors of learners[1][2]. Also, it is necessary to check the policy of foreign students and the Korean language training program of the government and the university through the understanding of the rapidly growing Korean learners[3-5].

In particular, considering that most of the foreign students are in their early 20s, it is likely that the intrinsic factors of the learner will have a greater impact on learning than the learning contents and system of the Korean language programs provided by the university's training

Received(August 26, 2018), Review Result(1st: September 14, 2018, 2nd: October 23, 2018), Accepted(December 10, 2018)

1) (Assistant Professor) 48520 School of Free Majors, Tongmyong University, Sinseonro 428, Nam-gu, Busan, Korea

email: kospora@naver.com 
institutes. According to Brown, learner factors affecting L2 learning vary, among which motivation is the most important of learner factors and is considered to be a factor that influences learning overall[6].

The purpose of this study is to examine motivation of Korean learners according to self determination motivation theory. For this research, I would like to investigate the motivation of students from Kuwait, China, and Vietnam and compare the results. Through this, we will examine the relationship between the nationality of foreign students and their motivation to learn Korean.

Deci and Ryan initially outlined the basic precepts of Self-Determination(SDT) in their book Intrinsic Motivation and Self-Determination in Human Behavior, published in 1985[7][8]. SDT has been adapted for use by several scholars in the field of SLL[9][10]. SDT has been found to be a valuable theoretical framework for understanding and explaining many different motivational orientations in a consistent and systematic manner[11].

SDT has also been shown to be empirically testable, allowing for clear predictions in the application of the theory to the language classroom[12]. SDT posits human motivation on a six-point continuum scale, from amotivation on the far left of the scale through four categories of extrinsic motivation, to intrinsic motivation on the far right of the scale. The four types of extrinsic motivation are external regulation, introjected regulation, identified regulation and integrated regulation[13]. This continuum is shown in [Fig. 1]
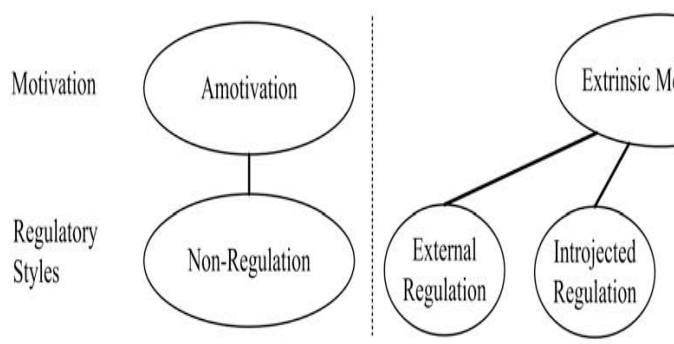

Relevant

Regulatory

Processes
Relevant Regulatory Processes
Compliance,

External Rewards and Punishments
Self-control, Ego-Involvement, Internal Rewards and Punishments

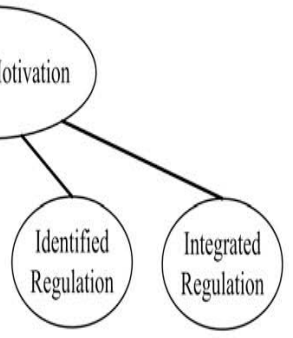

Personal Importance, Conscious Valuing

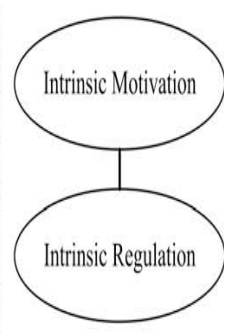

Interest, Enjoyment, Inherent Satisfaction

[Fig. 1] Continuum of Motivation based on SDT[12] 
Amotivation is a state where there is no incentive or motivation to engage in any activity by the learner. Students with this motivational stance show a low value, efficacy, and internal control for school activities. Amotivation is not a part of this study.

The integrated form of extrinsic motivation is also not a part of this study, as a foreign students have not had sufficient time to experience or develop such more advanced stage of extrinsic autonomy. Thus, both amotivation and integrated regulation are not included in the survey questionnaire, the Self-Regulation Questionnaire-Academic(SRQ-A). SRQ-A was used to develop statistical data for this study. The description of the four remaining categories used to measure student motivation is as follows[14].

External Regulations is the least autonomous form of extrinsic motivation, and includes being motivated by external rewards or punishment in the form of grades, monetary rewards, or the threat of parental disapproval. If rewards or punishment are removed, this type of motivation tends to disappear. Introjected Regulation are performed to avoid shame or guilt, or to attain feelings of esteem or self-worth. This type of behavior is somewhat more stable than external regulation, not depending solely on external rewards. Identified Regulation is a more self-determined form of motivation as there is a conscious acceptance of the behavior as personally important. Intrinsic Regulation is the most autonomous and self-determined type of motivation and tasks are performed out of a genuine interest and pleasure of the learner.

There have been many studies on learning motivation. However, there is a lack of research on the learning motivation of foreign students, their satisfaction toward classes. Therefore, this study aims to compare the difference of learning motivation according to the nationality of foreign students who have not been studied yet. With this basic theoretical framework in mind, this study will address the following two research questions:

1) What is the motivation for self-determination learning among international students?

2) what are the motivations for self-determination learning among groups by nationality?

\section{Methods}

\subsection{Participants}

The purpose of this study is to compare and analyze the results of existing study motives of Korean language learners. Therefore, we collected research data on Kuwait learners(KL), Chinese 
learners(CL), and Vietnamese learners(VL)

[Table 1] Participants

\begin{tabular}{|c|c|c|c|c|}
\hline \multirow{2}{*}{ Nationality } & \multicolumn{4}{|c|}{ Korean Language Proficiency } \\
\cline { 2 - 5 } & Beginner & Intermediate & Advanced & Total \\
\hline Kuwait & 33 & & 3 & 33 \\
\hline China & 51 & 23 & 4 & 77 \\
\hline Vietnam & 68 & 37 & & 109 \\
\hline
\end{tabular}

All Kuwait Korean learners are beginners. Of the Chinese Korean learners, 51 are beginners, 23 are intermediate, and 3 are advanced. 68 of the 109 Korean learners of Vietnamese, beginner, 37 intermediate, 4 advanced.

\subsection{Instrument}

A self-deterministic learning motive was measured using a questionnaire based on the Academic Self-Regulation Questionnaire(SRQ-A). Questionnaires were translated into Korean, Arabic, Chinese, and Vietnamese. The learning motivation suggested by the questionnaire consisted of six items: amotivation, external regulation, introjected regulation, identified regulation, integrated regulation, and intrinsic regulation. Each item was composed of 8 items, totaling 48 items. The measurement method was 6 points $(1=$ not at all, $2=$ very similar, $3=$ slightly less, 4 = slightly, 5 = slightly certain, 6 = surely), the higher the score, the higher the motivation of each type.

\subsection{Procedures and Data Analysis}

The collected data was analyzed using the SPSS 20.0 program. After completion of internal consistency reliability measurement, Pearson correlation analysis was performed to investigate the correlation between learning motivation types. Descriptive analysis, Pearson correlation analysis and analysis of variance(ANOVA) were then conducted to compare the motivations of self-determination among $\mathrm{KL}, \mathrm{CL}$, and VL.

In this study, questionnaire was revised to be applicable to foreign students. Firstly, the survey was carried out in the mode of mobile survey from June, 2017 to July, 2017. Data 
analysis was then conducted from July to december 2017 after the questionnaire collection was completed.

\section{Results}

\subsection{Correlation between Learning Motivation Types}

The results of the analysis are as follows. The correlation between types of learning motivation according to the nationality of foreign students is shown in the following [Table 2], [Table 3] and [Table 4]. Among Kuwait students, self-deterministic learning motivation showed the highest level of identified regulation, followed by integrated regulation, intrinsic regulation, introjected regulation, external regulation, and amotivation.

[Table 2] Pearson Correlation on Learning Motivation of Kuwait Learners

\begin{tabular}{|c|c|c|c|c|c|c|c|}
\hline Types & Item & & & & & & \\
\hline Amotivation & 8 & 1 & & & & & \\
\hline External Regulation & 8 & .071 & 1 & & & & \\
\hline Introjected Regulation & 8 & -.031 & $.429^{*}$ & 1 & & & \\
\hline Identified Regulation & 8 & -.155 & $.294^{*}$ & $.676^{* *}$ & 1 & & \\
\hline Integrated Regulation & 8 & -.231 & .227 & $.690^{* *}$ & $.871^{* *}$ & 1 & \\
\hline Intrinsic Regulation & 8 & -.300 & .321 & $.603^{* *}$ & $.833^{* *}$ & $.873^{* *}$ & 1 \\
\hline
\end{tabular}

${ }^{* *} \mathrm{p}<0.01$

In the case of Chinese international students, the result of measurement according to the type of learning motive was in the order of integrated regulation, identified regulation, intrinsic regulation, introjected regulation, external regulation, and amotivation. 
A Comparative Study on the Motivation for Self-Determination of Foreign Students Studying at Korea Universities

[Table 3] Pearson Correlation on Learning Motivation of Chinese Learners

\begin{tabular}{|c|c|c|c|c|c|c|c|}
\hline Types & Item & & & & & & \\
\hline Amotivation & 8 & 1 & & & & & \\
\hline External Regulation & 8 & $.562^{* *}$ & 1 & & & & \\
\hline Introjected Regulation & 8 & $.441^{* *}$ & $.871^{* *}$ & 1 & & & \\
\hline Identified Regulation & 8 & .120 & $.584^{* *}$ & $.735^{* *}$ & 1 & & \\
\hline Integrated Regulation & 8 & .134 & $.622^{* *}$ & $.773^{* *}$ & $.982^{* *}$ & 1 & \\
\hline Intrinsic Regulation & 8 & .160 & $.663^{* *}$ & $.818^{* *}$ & $.959^{* *}$ & $.978^{* *}$ & 1 \\
\hline
\end{tabular}

${ }^{* *} \mathrm{p}<0.01$

The learning motivations according to the type of learning motivation among Vietnamese student, the identified regulation showed the highest value, followed by intrinsic regulation, integrated regulation, introjected regulation, external regulation, and amotivation.

[Table 4] Pearson Correlation on Learning Motivation of Vietnamese Learners

\begin{tabular}{|c|c|c|c|c|c|c|c|}
\hline Types & Item & & & & & & \\
\hline Amotivation & 8 & 1 & & & & & \\
\hline External Regulation & 8 & $.631^{* *}$ & 1 & & & & \\
\hline Introjected Regulation & 8 & $.452^{* *}$ & $.811^{* *}$ & 1 & & & \\
\hline Identified Regulation & 8 & $.348^{* *}$ & $.646^{* *}$ & $.788^{* *}$ & 1 & & \\
\hline Integrated Regulation & 8 & $.429^{* *}$ & $.733^{* *}$ & $.827^{* *}$ & $.944^{* *}$ & 1 & \\
\hline Intrinsic Regulation & 8 & $.435^{* *}$ & $.725^{* *}$ & $.797^{* *}$ & $.961^{* *}$ & $.963^{* *}$ & 1 \\
\hline
\end{tabular}

$* * p<0.01$

\subsection{Nationality and Learning Motivation}

A descriptive statistical analysis was conducted to examine the differences in learning 
motivation according to the nationality of foreign students. According to the results of the analysis of variance, the motivation to learn according to nationality was high in order of Kuwait $(M=3.80)$, Vietnam $(M=3.41)$ and China $(M=3.20)$. And, the difference is statistically significant.

[Table 5] Descriptive Statistics

\begin{tabular}{|c|c|c|c|}
\hline Nationality & N. & M. & S.D. \\
\hline Vietnam & 109 & 3.4152 & .52516 \\
\hline China & 77 & 3.2085 & .56692 \\
\hline Kuwait & 33 & 3.8024 & .93211 \\
\hline total & 219 & 3.4009 & .64327 \\
\hline
\end{tabular}

In accordance to the significance level for the hypothesis "Are there differences in the motivation for learning Korean according to the nationality of the foreign student?", the lower the $\mathrm{p}$ value, the higher the $\mathrm{F}$ value, the more the difference between the groups. Therefore, there are differences in learning motivation depending on the learner 's nationality, and these differences were especially significant in the comparison between the two groups.

[Table 6] Analysis of Variance

\begin{tabular}{|c|c|c|c|c|c|}
\hline & sum of squares & $\mathrm{df}$ & M.S. & $\mathrm{F}$ & p-value \\
\hline between-group & 8.193 & 2 & 4.097 & 10.789 & .000 \\
\hline within-group & 82.014 & 216 & .380 & & \\
\hline total & 90.208 & 218 & & & \\
\hline
\end{tabular}

According to the nationality of the foreign students, there was a difference in the motivation to learn Korean language. As a result of the scheffe test, it was confirmed that there is difference between the groups. 
[Table 7] Scheffe Test

\begin{tabular}{|c|c|c|c|c|}
\hline \multirow{2}{*}{ Nationality } & M.D.(I-J) & S.E. & p-value \\
\hline \multirow{3}{*}{ Vietnam } & China & .20671 & .09173 & .081 \\
\cline { 2 - 5 } & Kuwait & $-.38723^{*}$ & .12243 & .008 \\
\hline \multirow{3}{*}{ China } & Vietnam & -.20671 & .09173 & .081 \\
\cline { 2 - 5 } & Kuwait & $-.59394^{*}$ & .12821 & .000 \\
\hline \multirow{3}{*}{ Kuwait } & Vietnam & $.38723^{*}$ & .12243 & .008 \\
\cline { 2 - 5 } & China & $.59394^{*}$ & .12821 & .000 \\
\hline
\end{tabular}

* Average difference is significant at the 0.05 level.

As the level of significance between Vietnamese and Chinese students was out of the range of .05, there was no difference in learning motivation between the two groups. However, the significance level between Kuwait students, Vietnamese students, Kuwait students and Chinese students is less than .05 .

\section{Conclusion}

The purpose of this study is to compare the learning motivation of students from Kuwait, China and Vietnam. For this purpose, 33 students from Kuwait, 77 from China, and 109 international students from Vietnam were selected as sample of study. And the motivations of learning were compared according to their nationality. The results showed that there were differences between Kuwait students and Chinese students; as well as between Kuwait students and Vietnamese students.

However, there was no statistically significant difference in learning motivation between Chinese and Vietnamese students. There are many foreign students from various nationalities studying together in Korea. There is a difference in learning motivation and purpose according to their respective nationality, and this difference has a great influence on studying abroad.

Among the various purposes of education, learner 's academic achievement can be a criterion for judging the success and failure of education. The academic achievement of the learner through the education will be influential even after the end of the study, and successful school 
Asia-pacific Journal of Convergent Research Interchange Vol.4, No.4 December 31 (2018), pp. 21-30

http://dx.doi.org/10.14257/apjcri.2018.12.03

life will lead to successful academic achievement. The most noteworthy topic for the learner to achieve high academic achievement is the motivation of learners. Learning motivation is the reason for the learner to succeed in their study, and it is the driving force that helps the student to continue their study[15].

Therefore, it is very important for foreign students of various nationalities to understand the language and culture of their counterparts while studying at Korean universities. In addition, it is necessary to observe and analyze various learning motives of foreign students to support smooth learning. It is also necessary to study and research Korean students who are studying with foreign students.

\section{References}

[1] M. Lee and S. Kim, A Study on the Motivation of Studying in Kuwait Students Based on Self-Deterministic Motivation Theory, Asia-pacific Journal of Multimedia Services Convergent with Art, Humanities, and Sociology, (2018), Vol.8, No.2, pp.515-523.

[2] M. Lee and S. Kim, A Study on the Comparison of Learning Motivation between Korean and Foreign Students, The Convergent Research Society Among Humanities, Sociology, Science and Technology, Convergence Research Letters, (2018), Vol.4, No.1, pp.761-765.

[3] S. Kim, A Study on the Correlation between Self-Determination Intervention and Learning Motivation, The Convergent Research Society Among Humanities, Sociology, Science and Technology, Convergence Research Letters, (2018), Vol.4, No.1, pp.767-771.

[4] A. Kim, validation of taxonomy of academic Motivation based on the self-determination theory, Korean Journal of Educational Psychology, (2002), Vol.16, No.4, pp.169-187.

[5] Y. Jung, A Study on the Self-determination Motivation of Saudi Arabians as korean Language learners, Journal of Learner-Centered Curriculum and Instruction, (2016), Vol.16, No.7, pp.319-338.

[6] B. Bak, J. Lee and S. Hong, Reconstructing the classificatory pattern of Learning motivation proposed by self-determination theory, Korean Journal of educational Psychology, (2005), Vol.19, No.3, pp.699-717.

[7] Z. Dörnyei and R. Schmidt, Motivation and second language acquisition, Honolulu, HI: University of Hawai'i Press, (2001)

[8] K. Noels, R. Clément and L. Pelletier, Perceptions of teacher communicative style and students' intrinsic and extrinsic motivation, Modern Language Journal, (1999), Vol.83, No.2, pp.23-34.

[9] M. Williams and B. Burden, Psychology for language teachers: A social constructivist approach, Cambridge: Cambridge University Press, (1997)

[10] L. Vandergrift, Relationships among motivation orientations, meta cognitive awareness and proficiency in L2 listening, Applied Linguistics, (2005), Vol.26, No.1, pp.70-89. 
[11] L. Noels, L. Pelletier and R. Vallerand, Why are you learning a second langauge? Motivational orientations and self-determination theory, Language Learning, (2003), Vol.53, No.1, pp.33-63.

[12] E. L. Deci and R. Ryan, Intrinsic motivation and self-determination in human behavior, New York: Plenum, (1985)

[13] R. Vallerand, Toward a hierarchical model of intrinsic and extrinsic motivation, Advances in Experimental Psychology, (1997), Vol.29, pp.271-360.

[14] B. Murray, Classroom motivation of Korean EFL students from the perspective of self-determination theory, English Teaching, (2007), Vol.62, No.4, pp.391-409.

[15] J. Hong, A Study on the Motivation of Migrant Youth as Korean Language Learner-Focusing on the Self-determination Motivation of Chinese Students-, The Journal of Language \& Literature, (2014), Vol.60, pp. $421-466$. 